\title{
Long-acting reversible contraception utilization and associated factors among women in extended postpartum period in Hossana town, southern Ethiopia: cross sectional study
}

\author{
Biruktawit Fekade Woldu ${ }^{1 *}$ (D), Tadesse Lelago Ermolo², Lidiya Gutema Lemu ${ }^{3}$ and Negeso Gebeyehu Gejo
}

\begin{abstract}
Background: In low and middle-income countries, 95\% of postpartum women want to avoid a pregnancy for 2 years, but $70 \%$ are not using contraception. Delay in use of contraception by couples during postpartum period can result in many unwanted pregnancies. Long-acting reversible contraception (LARC) is ideal for postpartum women. Therefore this study aimed at assessing the prevalence and factors associated with LARC use among postpartum women.

Methods: Facility based cross sectional study was conducted from July 23-Aug 25, 2018. Systematic random sampling technique was employed to recruit a total of 381 women in extended postpartum period visiting Child Immunization service in hosanna health institutions. Pretested structured questionnaire was used for data collection. Data was analyzed by SPSS version 20. Binary and multiple logistic regression analysis was done. The presence and strength of association was determined using AOR with its $95 \% \mathrm{Cl}$. Variables with $P$ value less than 0.05 were considered as statistical significant.

Results: The prevalence of LARC use was 36.5\% (95\%CI (33.05-39.95)). The main reason for not using LARC was fear of side effect and false information. Previous use of $L A R C(A O R=3.3,95 \% \mathrm{Cl}(1.7-6.5))$ and have ever discussed with health providers on $\operatorname{LARC}(A O R=2.5,95 \% \mathrm{Cl}(1.1-5.74))$ were found to be significantly associated with $L A R C$ use. Conclusions: The utilization of LARC among postpartum women was found to be higher than other studies in Ethiopia. Provision of effective contraceptive counseling during Antenatal, delivery and postnatal care services with emphasis on LARC/Postpartum Intra-Uterine Device is important.
\end{abstract}

Keywords: Long-acting, Contraception, Postpartum, Prevalence, Factors, Hossana

\footnotetext{
* Correspondence: biruktifekade@gmail.com

'Department of Midwifery, College of Medicine and Health Sciences, Wachemo University, Hossana, Ethiopia

Full list of author information is available at the end of the article
}

(c) The Author(s). 2020 Open Access This article is licensed under a Creative Commons Attribution 4.0 International License, which permits use, sharing, adaptation, distribution and reproduction in any medium or format, as long as you give appropriate credit to the original author(s) and the source, provide a link to the Creative Commons licence, and indicate if changes were made. The images or other third party material in this article are included in the article's Creative Commons licence, unless indicated otherwise in a credit line to the material. If material is not included in the article's Creative Commons licence and your intended use is not permitted by statutory regulation or exceeds the permitted use, you will need to obtain permission directly from the copyright holder. To view a copy of this licence, visit http://creativecommons.org/licenses/by/4.0/. The Creative Commons Public Domain Dedication waiver (http://creativecommons.org/publicdomain/zero/1.0/) applies to the data made available in this article, unless otherwise stated in a credit line to the data. 


\section{Background}

After one-time placement of a device, Long-acting reversible contraception (LARC) methods provide reliable long-term highly effective prevention of pregnancy. LARC methods include subdermal hormonal implant and Intra-Uterine Devices (hormonal IUDs and nonhormonal copper-containing IUDs) [1]. Regardless of considerable advances in contraceptive technologies, unintended pregnancies remain a significant global public health issue. In developing countries 214 million reproductive age women who desire to avoid pregnancy are not using a modern contraceptive method $[2,3]$.

Modern contraceptive use has increased around the world. However, less than $15 \%$ of married women of reproductive age use a modern method in many of the poorest countries. The use of LARC among modern contraception users is still low [4]. In Ethiopia, Contraceptive prevalence rate among currently married women has increased steadily from $14 \%$ in 2005 to $41 \%$ in 2019 . The largest increase is observed in the use of injectable. The use of LARC remains low at $11 \%$ (9\%- Implants \& $2 \%$-IUD) [5]. In southern region, where the study area is located, $44.6 \%$ of currently married women were using a modern family planning. Among these only 9.2\% use LARC (7.7\%- Implants \& 1.5\%IUD). Utilization of LARC was found to have significant association with women's socio-demographic and reproductive characteristics. Knowledge, attitude and previous LARCs use was also found to have significant association with its use [6-14].

In the first year after childbirth, 95\% of women in low and middle-income countries want to avoid pregnancy within the next 2 years; however $70 \%$ are not using contraception. Delay in practice of contraception by couples during postpartum period can result in many unwanted or mistimed pregnancies. A woman conceives within/less than 24 months of delivery has higher chances of complications like abortions, pre-term labor, low birth weight babies, postpartum hemorrhage, neonatal morbidity and mortality [15]. Postpartum family planning is defined as the prevention of unintended pregnancy and closely spaced pregnancies through the first 12 months following childbirth [16]. Postpartum period is one of the important and crucial times when women and couples are highly motivated and receptive to family planning methods. LARC methods are safe for almost all women, including those in a postpartum period [2]. As they do not contain estrogen and have few contraindications, they are ideal for use in postpartum women [17]. According to a study in five lowincome countries, almost all women wish to delay or prevent a future pregnancy at six weeks postpartum. Despite this, usage of modern contraceptive methods at 42 days post-partum varied widely. The uptake of the most effective LARC (IUDs) is very low even amongst users of modern contraceptives [18]. Different studies conducted in different parts of Ethiopia also indicated lower prevalence of postpartum LARC use [19-24]. Study on LARC use among postpartum women is lacking in the study area. Therefore the objective of this study was to assess the prevalence and factors associated with LARC use among women in extended postpartum period visiting child immunization in Hosanna health institutions, Southern Ethiopia.

\section{Methods}

\section{Study setting and population}

Facility based cross sectional study was conducted from July 23-Aug 25, 2018 in hosanna health institutions, Hadiya zone Southern Ethiopia. Hossana town comprises of three sub cities and eight kebeles(the lowest governmental administrative units). According to CSA population count of May 2007, the total number of Hossana town population was 69,959 for the year $2007 / 8$. Among these 34,454 (49.25\%) were females. There is 1 teaching referral hospital and 3 health centers in the town which provide postpartum family planning service. Women in extended postpartum period visiting child immunization service in the four health institutions during the study period were eligible for enrollment. Those women who are pregnant and unable to speak or hear were excluded from the study.

\section{Sample size determination and sampling technique}

Sample size was calculated using single population proportion formula by taking account of Proportion of LARC use among postpartum women in Durame town $36.7 \%$ [13], $\mathrm{CI}=95 \%$ Margin of error $=5$ and $10 \%$ nonresponse rate. A total of 392 women on extended postpartum period ( 6 weeks to 1 year after delivery) were invited to participate. Systematic random sampling technique was employed to select participants. The total number of women who visit child Immunization (N) was estimated by considering the immediate previous 1 month record of Expanded Program on Immunization chart. Then number of sampling intervals $(\mathrm{k})$ was determined by dividing $\mathrm{N}$ by sample size $(n=392)$. Then lottery method was used to select the first participant. Then after every 3rd unit was included until the required sample reached. In case of refusal or not meeting inclusion criteria, the next person was selected. The sample size for each institution was distributed proportionally.

\section{Data collection}

Data were collected using pretested, interviewer administered structured questionnaire. The questionnaire was adapted from different literatures by considering the local situation of the study subjects. Information on 
participants' socio-demographic, reproductive characteristics, knowledge, attitude and practice towards LARC was collected. The data collection tool prepared in English was translated in to Amharic and then returned back to English to ensure accuracy. Before the actual data collection, Pre-test was done on $5 \%$ women in a health center located outside the town and necessary corrections made accordingly. Four trained diploma midwifery graduates collected the data supervised by one BSc midwife working in university. Completeness of the questionnaires was checked on the spot by supervisor.

\section{Measurement}

LARC use: was defined as utilization of any of LARCs (IUD or subdermal hormonal implant) by women on extended postpartum period.

The mean score was used to categorize women's knowledge towards LARC; women who scored above mean score were considered to have good knowledge and women who scored below the mean were considered to have poor knowledge.

Women's attitude towards LARC was categorized in the same approach. Those women who scored above the mean were considered to have positive attitude and scored below the mean considered to have negative attitude towards LARC.

\section{Data analysis}

Data was analyzed by using SPSS version 20. Descriptive statistics were computed. Binary logistic regression analysis was done and all explanatory variables with $p$ value less than 0.2 were entered to multiple logistic regression model. The second analytical step used a stepwise backward model. Then association was assessed using AOR and its $95 \% \mathrm{CI}$. And $p$ value of $<0.05$ was considered as statistically significant. Goodness of model fitness was tested by using Hosmer and Lemeshow test.

\section{Results}

Data were analyzed from 381 women, making response rate of $97.1 \%$. Mean age of participants were $27(\mathrm{SD} \pm$ 4.6). Majority of participants were urban resident (89\%). Less than one fifth of respondents attend diploma and above level of education (17.1\%). Half of the women were housewife (50.4\%) (Table 1).

\section{Reproductive characteristics of respondents}

More than two-third (71\%) of participants had two or more births. Median number of alive children per women and birth interval were 2 IQR $[1,4]$ and 36 months IQR $[24,48]$ respectively. Around one-third (28.3\%) participants do not want any more children for the future.
Table 1 Sociodemographic characteristics of postpartum women in Hossana health institutions, 2018 $(n=381)$

\begin{tabular}{|c|c|c|}
\hline Variable & Frequency & Percentage \\
\hline \multicolumn{3}{|l|}{ Age (years) } \\
\hline $16-20$ & 31 & 8.1 \\
\hline $21-25$ & 124 & 32.5 \\
\hline $26-30$ & 154 & 40.4 \\
\hline $31-35$ & 50 & 13.1 \\
\hline $36-40$ & 22 & 5.8 \\
\hline \multicolumn{3}{|l|}{ Residence } \\
\hline Urban & 339 & 89.0 \\
\hline Rural & 42 & 11.0 \\
\hline \multicolumn{3}{|l|}{ Marital status } \\
\hline Married & 369 & 96.9 \\
\hline Single & 7 & 1.8 \\
\hline Separated & 5 & 1.3 \\
\hline \multicolumn{3}{|l|}{ Educational status } \\
\hline Can't read and write & 15 & 3.9 \\
\hline Can Read \& Write & 19 & 5.0 \\
\hline Primary & 141 & 37.0 \\
\hline Secondary & 141 & 37.0 \\
\hline Diploma \& Above & 65 & 17.1 \\
\hline \multicolumn{3}{|l|}{ Working status } \\
\hline Housewife & 192 & 50.4 \\
\hline Merchant & 51 & 13.4 \\
\hline Government Employee & 67 & 17.6 \\
\hline Private Employee & 58 & 15.2 \\
\hline Other & 13 & 3.4 \\
\hline
\end{tabular}

Less than one fifth of respondents (18.1\%) intended to give birth within 2 years. More than one-forth (28.6\%) had never discussed with health professionals towards LARC and $52.4 \%$ were advised on LARC during the immediate postpartum period (Table 2).

\section{Knowledge, attitude and previous LARC use}

More than two-third (71.4\%) of the women had good knowledge towards LARC. Around half of them (53.2\%) had positive attitude towards LARC. Two-third (68.5\%) of participant's partner had supportive attitude towards LARC. Two-third (66.4\%) of respondents had ever used at least one type of modern contraception and one-fourth (26\%) had ever used LARC before delivery of last child (Table 3).

\section{Prevalence of postpartum LARC use}

Two-third (66.6\%) of postpartum women had started to use modern family planning method. LARC method use among participants was $36.5 \%$ (implant $34.1 \%$, IUCD- 
Table 2 Reproductive characteristics of postpartum women in Hossana health institutions, $2018(n=381)$

\begin{tabular}{|c|c|c|}
\hline \multirow[t]{2}{*}{ Variable } & \multicolumn{2}{|l|}{ LARC use } \\
\hline & $\begin{array}{l}\text { Yes } \\
n(\%)\end{array}$ & $\begin{array}{l}\text { No } \\
\text { n(\%) }\end{array}$ \\
\hline \multicolumn{3}{|l|}{ Parity } \\
\hline 1 & $72(65.5)$ & $38(34.5)$ \\
\hline $2-4$ & 137(61.7) & 85(38.3) \\
\hline$\geq 5$ & $33(67.3)$ & $16(32.7)$ \\
\hline \multicolumn{3}{|c|}{ Number of alive children } \\
\hline 1 & $75(65.8)$ & $39(34.2)$ \\
\hline $2-4$ & 135(60.8) & $87(39.2)$ \\
\hline$\geq 5$ & $32(71.1)$ & 13(28.9) \\
\hline \multicolumn{3}{|l|}{ Place of last birth } \\
\hline Home & 15(71.4) & $6(28.6)$ \\
\hline Health institution & $227(63.1)$ & 133(36.9) \\
\hline \multicolumn{3}{|c|}{ Birth interval(in month) $(n=272)$} \\
\hline $0-23$ & $28(73.7)$ & $10(26.3)$ \\
\hline $24-35$ & $56(64.4)$ & $31(35.6)$ \\
\hline $36 \&$ above & $87(59.2)$ & $60(40.8)$ \\
\hline \multicolumn{3}{|c|}{ Number of children want for the future } \\
\hline 0 & $74(68.5)$ & $34(31.5)$ \\
\hline $1-3$ & 131(59.8) & $88(40.2)$ \\
\hline $4-6$ & $37(68.5)$ & 17(31.5) \\
\hline \multicolumn{3}{|c|}{ Intended to give birth within 2 years $(n=273)$} \\
\hline Yes & $49(71.0)$ & $20(29.0)$ \\
\hline No & 119(58.3) & $85(41.7)$ \\
\hline \multicolumn{3}{|c|}{ Ever discussed with health professionals } \\
\hline Yes & $123(45.2)$ & $149(54.8)$ \\
\hline No & $16(14.7)$ & $93(85.3)$ \\
\hline \multicolumn{3}{|c|}{ Advised during immediate postpartum } \\
\hline Yes & $95(47.5)$ & 105(52.5) \\
\hline No & $44(24.3)$ & 137(75.7) \\
\hline
\end{tabular}

Table 3 Knowledge, attitude and previous LARC use among postpartum women in Hossana health institutions, 2018( $n=381)$

\begin{tabular}{lll}
\hline Variable & \multicolumn{2}{l}{ LARC use } \\
\cline { 2 - 3 } & Yes & No \\
\hline Knowledge towards LARC & $121(44.5 \%)$ & $151(55.5 \%)$ \\
Good & $18(16.5 \%)$ & $91(83.5 \%)$ \\
Poor & & \\
Attitude towards LARC & $77(41.8 \%)$ & $107(58.2 \%)$ \\
Positve & $61(38.4 \%)$ & $98(61.6 \%)$ \\
Negative & & $40(40.8 \%)$ \\
Previous LARC use & $58(59.2 \%)$ & $202(71.4 \%)$ \\
Used before & $81(28.6 \%)$ & \\
Never used & &
\end{tabular}

2.4\%). The main reason for not using LARC was fear of side effect (39.3\%) followed by false rumors towards LARC (it cause harm to uterus, infertility, interfere with work, fly/lost in the body) (21.9\%) (Table 4).

\section{Factors associated with LARC use}

In the multiple logistic regression analysis Previous LARC use and ever discussed with Health Professionals on LARC were found to be significantly associated with LARC use. Those women who have ever used LARC before were 3.3 times more likely to use LARC on postpartum period $(\mathrm{AOR}=3.3,95 \% \mathrm{CI}(1.7-6.5)$. Postpartum women who have ever discussed with health professionals on LARC were 2.5 times more likely to use LARC $($ AOR $=2.5$, 95\% CI (1.1-5.7) $)$ (Table 5).

\section{Discussion}

In this study the prevalence of LARC use among postpartum women was found to be $36.5 \%$ (95\%CI (33.0539.95)), which is similar with a study done in Durame [13]. However it is higher than a study in Northern Ethiopia [24]. The difference can be due to variation in participants' characteristics and institution based nature of our study.

Majority of LARC users opted for Implant (93.5\%) and very few used IUCD (6.5\%). Which is consistent with different studies $[6,14]$ where strong preference for implants over IUCD were observed. These can be due to prevailing misinformation towards IUCD.

The main reason for not using LARC among postpartum women was fear of side effect (39.3\%) followed by false information towards LARC (it cause harm to uterus and infertility, interfere work, fly/lost in the body) (21.9\%) which is consistent with other study [8]. This indicates the need of community based health education and awareness creation programs.

In this study previous LARC use was found to be significantly associated with postpartum LARC use (AOR = 3.34 (1.70-6.55)). Similar finding were indicated by other studies $[10,13]$. The possible explanation can be women possibly will have adequate information on the contraception method they used before, which can motivate them to use the same method repetitively.

Table 4 method-mix adopted among postpartum women in Hossana health institutions, 2018 $(n=381)$

\begin{tabular}{lll}
\hline Contraception method & Frequency & Percentage \\
\hline Injectable & 98 & 25.7 \\
Implants & 130 & 34.1 \\
IUCD & 9 & 2.4 \\
Pills & 15 & 3.9 \\
Condom & 2 & 0.5 \\
Non users & 127 & 33.4 \\
\hline
\end{tabular}


Table 5 Logistic regression analysis of factors associated with LARC use among postpartum women in hossana health institutions, $2018(n=381)$

\begin{tabular}{|c|c|c|c|c|}
\hline \multirow[t]{2}{*}{ Variable } & \multicolumn{2}{|l|}{ LARC use } & \multirow[t]{2}{*}{ COR $(95 \% \mathrm{Cl})$} & \multirow[t]{2}{*}{ AOR $(95 \% C l)$} \\
\hline & Yes (n\%) & No $(n \%)$ & & \\
\hline \multicolumn{5}{|l|}{ Residence } \\
\hline Urban & 130(38.3) & 209(61.7) & 1 & \\
\hline Rural & $9(21.4)$ & $33(78.6)$ & $0.43(.20-.94)$ & $0.53(0.19-1.42)$ \\
\hline \multicolumn{5}{|c|}{ Intention to give birth within 2 years } \\
\hline Yes & $20(29.0)$ & 49(71.0) & 1 & \\
\hline No & $85(41.7)$ & 119(58.3) & $1.75(.97-3.15)$ & $1.82(0.94-3.54)$ \\
\hline \multicolumn{5}{|c|}{ Knowledge towards LARC } \\
\hline Good & $121(44.5)$ & $151(55.5)$ & $4.01(2.31-7.08)$ & $0.95(0.43-2.10)$ \\
\hline Poor & $18(16.5)$ & $91(83.5)$ & 1 & \\
\hline \multicolumn{5}{|l|}{ Partner attitude } \\
\hline Supportive & $118(45.2)$ & $143(54.8)$ & $2.59(1.48-4.54)$ & $0.50(0.24-1.03)$ \\
\hline Not supportive & $20(24.1)$ & $63(75.9)$ & 1 & \\
\hline \multicolumn{5}{|l|}{ Previous LARC use } \\
\hline Yes & $58(59.2)$ & $40(40.8)$ & $3.61(2.24-5.83)$ & $3.34(1.70-6.55)^{*}$ \\
\hline No & $81(28.6)$ & $202(71.4)$ & 1 & \\
\hline \multicolumn{5}{|c|}{ Adviced during immediate postpartum } \\
\hline Yes & $95(47.5)$ & $105(52.5)$ & $2.81(1.81-4.36)$ & $1.26(0.66-2.42)$ \\
\hline No & $44(24.3)$ & 137(75.7) & 1 & \\
\hline \multicolumn{5}{|c|}{ Ever discussed on LARC with professionals } \\
\hline Yes & 123(45.2) & $149(54.8)$ & $4.79(2.68-8.58)$ & $2.56(1.14-5.74)^{* *}$ \\
\hline No & $16(14.7)$ & $93(85.3)$ & 1 & \\
\hline
\end{tabular}

*Significant at $<0.05 * *$ significant at $<0.001$

Those postpartum women who ever discussed with health professionals on LARC were found to be more likely to use LARC $(\mathrm{AOR}=2.569(1.148-5.7470))$. It is in line with another study [6]. This can possibly explained by the fact that access to clear factual information on the benefits and limitations of contraceptive methods is imperative to promote informed choice and to overcome misperceptions and myths more broadly perpetuated in the community.

\section{Limitation}

Quantitative nature of the study hinders indepth exploration of women's perception and barrieres for LARC use. As this study was conducted in urban facilities, the finding might not be representative for the rural communities.

\section{Conclusion}

The utilization of LARC among postpartum women was found to be higher than other studies done in Ethiopia. Majority of participants opted for implants over IUCD. The main reason for not using LARC was fear of side effect and rumors. Provision of effective contraceptive counseling during Antenatal, delivery and postnatal care services with emphasis on LARC/ PPIUDs is important. Further studies need to be conducted to assess women's knowledge, perceptions and attitudes towards PPIUDs.

\section{Acknowledgements}

We are indebted to data collectors and all women who agreed to participate in this study. We want to thank health institution administrators for their great collaboration.

\section{Authors' contributions}

$B F W$, TLE, and LGL contributed to the initiation of the study, design, organizing the data collection process and analysis of the result. BFW, TLE, LGL and NGG involved in writing of the manuscript. All authors read and approved the final manuscript.

Funding

This study was conducted by the fund obtained from Wachemo University

\section{Availability of data and materials}

The datasets used and/or analysed during the current study are available from the corresponding author on reasonable request.

\section{Ethics approval and consent to participate}

Ethical approval was obtained from wachemo university ethical review committee. Cooperation letter submitted to health institutions. The 
objective, benefit and risks of the study were explained and informed written consent obtained from all respondents. The attainment of confidentiality was assured for participants.

\section{Consent for publication}

Not applicable(3).

\section{Competing interests}

The authors proclaim that they have no competing interests.

\section{Author details}

'Department of Midwifery, College of Medicine and Health Sciences, Wachemo University, Hossana, Ethiopia. ${ }^{2}$ Department of Nursing, College of Medicine and Health Sciences, Wachemo University, Hossana, Ethiopia. ${ }^{3}$ Department of Midwifery, College of Health Sciences, Mizan Tepi University, Mizan Aman, Ethiopia.

Received: 25 December 2019 Accepted: 23 July 2020

Published online: 05 August 2020

\section{References}

1. Winner B, Peipert JF, Zhao Q, Buckel C, Madden T, Allsworth J, et al. Effectiveness of long-acting reversible contraception. N Engl J Med. 2012; 366:1998-2007.

2. WHO. Family planning/Contraception Fact sheet. In: WHO, editor. 2017.

3. Curtis KM, Peipert JF. Long-acting reversible contraception. N Engl J Med. 2017;376:461-8. https://doi.org/10.1056/NEJMcp1608736.

4. Family Planning Worldwide 2019 Data Sheet www.prb.org/pdf19/ familyplanning-2019-datasheet_eng.pdf, Accessed 11 Dec 2019.

5. Central Statistical Agency (CSA) [Ethiopia] and ICF. 2019. Ethiopia mini demographic and health survey 2019: key indicators report. Addis Ababa, Ethiopia, and Rockville, Maryland, USA. CSA and ICF. https://dhsprogram. com/pubs/pdf/PR120/PR120.pdf.

6. Taye A, Woldie M, Sinaga M. Predictors of Long Acting Reversible Contraceptive use among Married Women Visiting Health Facilities in Jimma Town. J Women's Health Care. 2014:4:217. https://doi.org/10.4172/ 2167-0420.1000217, https://www.researchgate.net/profile/Mirkuzie_Woldie2/ publication/273128776_Predictors_of_Long_Acting_Reversible Contraceptive_use_among_Married_Women_Visiting_Health_Facilities_in_ Jimma_Town/links/550749090cf2d7a28123bea4/Predictors-of-Long-ActingReversible-Contraceptive-use-among-Married-Women-Visiting-HealthFacilities-in-Jimma-Town.pdf.

7. Shegaw G, Mohammed AA, Nadew K, Tamrat K, Zeru G, Desta H, Yinager W. Long acting contraceptive method utilization and associated factors among reproductive age women in Arba Minch Town, Ethiopia. Greener J Epidemiol Public Health. 2014;2(1):023-031.

8. Gebremichael H, Haile F, Dessie A, Birhane A, Alemayehu M, Yebyo H. Acceptance of long acting contraceptive methods and associated factors among women in Mekelle City, Northern Ethiopia. Sci J Public Health. 2014; 2(4):239-45.

9. Kabalo MY. Utilization of reversible long acting family planning methods among married 15-49 years women in Areka town, Southern Ethiopia. Int J Sci Rep. 2016;2(1):1-6. http://www.sci-rep.com.

10. Melka AS, Tekelab T, Wirtu D. Determinants of long acting and permanent contraceptive methods utilization among married women of reproductive age groups in western Ethiopia: a cross-sectional study. Pan Afr Med J. 2015;21:246

11. Austad K, Shah P, Rohloff P. Correlates of long-acting reversible contraception uptake among rural women in Guatemala. PLOSONE. 2018; 13(6):e0199536. https://doi.org/10.1371/journal.pone.0199536.

12. Teferra AS, Wondifraw AA. Determinants of Long Acting Contraceptive Use among Reproductive Age Women in Ethiopia: Evidence from EDHS 2011. Sci J Public Health. 2014;3(1):143-9. https://doi.org/10.11648/j.sjph.20150301. 33.

13. Tamrie YE, Hanna EG, Argaw MD. Determinants of long acting reversible contraception method use among mothers in extended postpartum period Durame Town, Southern Ethiopia: a cross sectional community based survey. Health. 2015;7:1315-26. https://doi.org/10.4236/health.2015.710146.

14. Gudaynhe SW, Zegeye DT, Tarekegn A, Kibret GD. Factors affecting the use of long-acting reversible contraceptive methods among married women in
Debre Markos Town, Northwest Ethiopia 2013. Glob J Med Res. 2014;14(5) https://medicalresearchjournal.org/index.php/GJMR/article/view/783.

15. Shoupe D. LARC methods: entering a new age of contraception and reproductive health contraception and reproductive medicine. 2016;1(4). https://doi.org/10.1186/s40834-016-0011-8, http://creativecommons.org/ publicdomain/zero/1.0/

16. World Health Organization. Programming strategies for postpartum family planning 2013. https://www.who.int/reproductivehealth/publications/ family_planning/ppfp_strategies/en/.

17. Parks C, Peipert F. Eliminating Health Disparities in Unintended Pregnancy with Long-Acting Reversible Contraception (LARC) Am J Obstet Gynecol. 2016;214(6):681688. https://doi.org/10.1016/j.ajog.2016.02.017, https://www. ncbi.n/m.nih.gov/pmc/articles/PMC4884485/.

18. Pasha O, Goudar SS, Patel A, Garces A, Esamai F, Chomba E, et al. Postpartum contraceptive use and unmet need for family planning in five low-income countries. Reprod Health. 2015;12(2):S11. https://www.ncbi.nIm. nih.gov/pubmed/26063346.

19. Abera Y, Mengesha ZB, Tessema GA. Postpartum contraceptive use in Gondar town, Northwest Ethiopia: a community based cross-sectional study. BMC Womens Health. 2015:15(1):19.

20. Gebremedhin AY, Kebede Y, Gelagay AA, Habitu YA. Family planning use and its associated factors among women in the extended postpartum period in Addis Ababa, Ethiopia. Contracept Reprod Med. 2018;3(1):1.

21. Abraha TH, Gebrezgiabher BB, Aregawi BG, Belay DS, Tikue LT, Welay GM. Predictors of postpartum contraceptive use in rural Tigray region, northern Ethiopia: a multilevel analysis. BMC Public Health. 2018;18(1):1017.

22. Gebremariam A, Gebremariam H. Contraceptive use among lactating women in Ganta-Afeshum District, Eastern Tigray, Northern Ethiopia, 2015: a cross sectional study. BMC Pregnancy Childbirth. 2017;17(1):421.

23. Demie T, Demissew T, Huluka T, Workineh F, Libanos H. Postpartum family planning utilization among postpartum women in public health institutions of Debre Berhan town, Ethiopia. J Women's Health Care. 2018;7:2. 2018; 7(426):2167-0420.

24. Mengesha ZB, Worku AG, Feleke SA. Contraceptive adoption in the extended postpartum period is low in Northwest Ethiopia. BMC Pregnancy Childbirth. 2015;15(1):160. https://bmcpregnancychildbirth.biomedcentral. com/articles/10.1186/s12884-015-0598-9.

\section{Publisher's Note}

Springer Nature remains neutral with regard to jurisdictional claims in published maps and institutional affiliations.

Ready to submit your research? Choose BMC and benefit from:

- fast, convenient online submission

- thorough peer review by experienced researchers in your field

- rapid publication on acceptance

- support for research data, including large and complex data types

- gold Open Access which fosters wider collaboration and increased citations

- maximum visibility for your research: over $100 \mathrm{M}$ website views per year

At BMC, research is always in progress.

Learn more biomedcentral.com/submission 